\title{
Erratum: A phosphorylation switch controls the spatiotemporal activation of Rho GTPases in directional cell migration
}

\author{
Xuan Cao, Tomonori Kaneko, Jenny S. Li, An-Dong Liu, Courtney Voss \& Shawn S.C. Li
}

Nature Communications 6:7721 doi: 10.1038/ncomms8721 (2015); Published 13 Jul 2015; Updated 8 Sep 2015

The image in Fig. 1h of this Article was inadvertently duplicated from panel i. The correct version of the figure appears below.

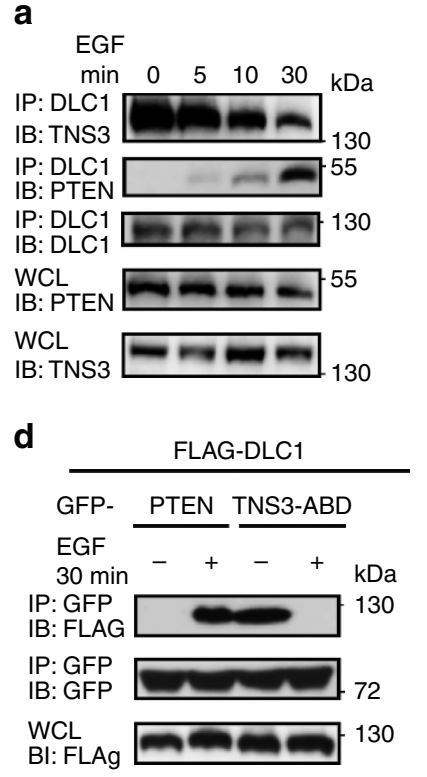

g

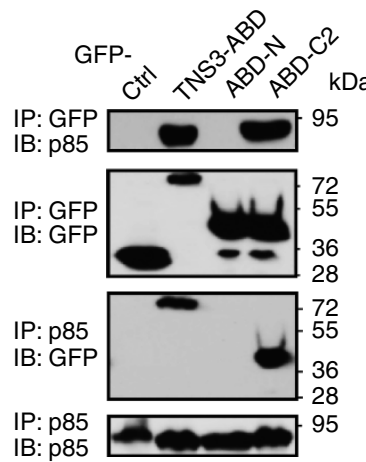

b

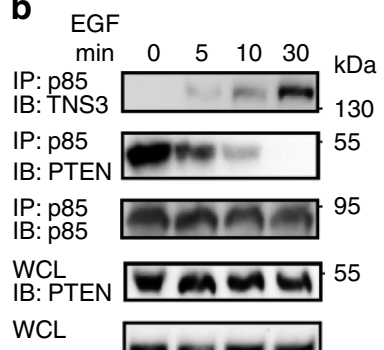

IB:TNS3 130

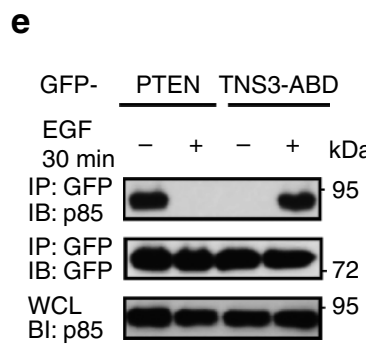

h

FLAG-DLC1

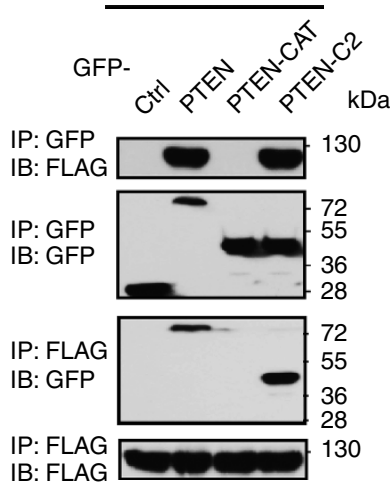

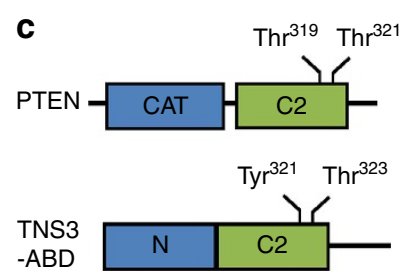

$-A B D$

f
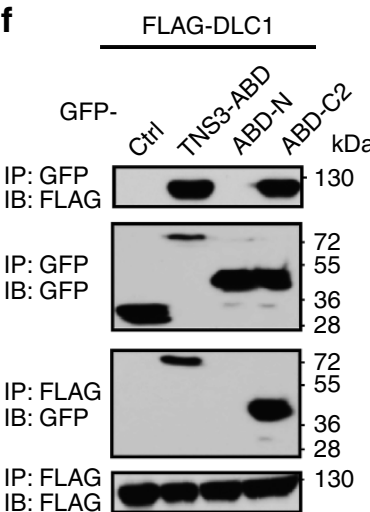

i

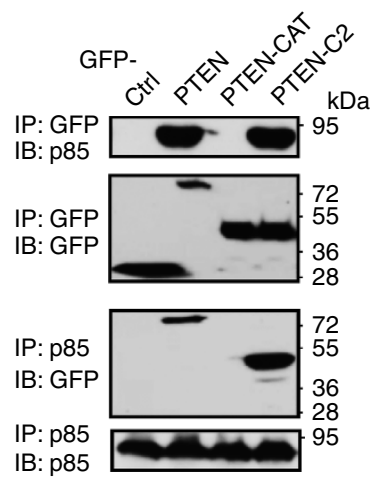


(c) (i) This work is licensed under a Creative Commons Attribution 4.0 International License. The images or other third party material in this article are included in the article's Creative Commons license, unless indicated otherwise in the credit line; if the material is not included under the Creative Commons license, users will need to obtain permission from the license holder to reproduce the material. To view a copy of this license, visit http://creativecommons.org/licenses/by/4.0/ 